\title{
Endoscopic Management of Obesity 2020
}

\author{
Truptesh H Kothari
}

\begin{abstract}
Obesity is a disease of energy homeostasis with accumulation of excessive fat leading to negative health effects associated with increased morbidity and mortality. The World Health Organization (WHO) estimates approximately 700 million people worldwide in the obese category. Life expectancy due to obesity is decreased by 6-7 years. A body mass index (BMI) of $30-35 \mathrm{~kg} / \mathrm{m}^{2}$ reduces life expectancy by 2-4 years, while $\mathrm{BMI}>40 \mathrm{~kg} / \mathrm{m}^{2}$ reduces life expectancy by 10 years. In this manuscript, we will review the global updates on the burden of obesity, current management of obesity, evolution of bariatric endotherapy, various aspects of bariatric endotherapy, and literature review of the data supporting the bariatric endotherapy.

Keywords: Aspiration therapy, Endoscopic bariatric therapy, Endoscopic sleeve gastroplasty, Intragastric balloons, Obesity, Transoral outlet reduction endoscopy.

Journal of Postgraduate Medicine, Education and Research (2021): 10.5005/jp-journals-10028-1426
\end{abstract}

More than one-third of American adults today suffer from obesity, defined by a body mass index $(\mathrm{BMI}) \geq 30 \mathrm{~kg} / \mathrm{m}^{2}$. Obesity is associated with increased morbidity and mortality, accounting for an estimated $\$ 147$ billion in United States (US) medical costs annually. ${ }^{1-4}$

Obesity is classified into three categories based on BMI. BMI ranging from 25 to $29.9 \mathrm{~kg} / \mathrm{m}^{2}$ falls in the overweight category. BMI from 29.9 to $34.9 \mathrm{~kg} / \mathrm{m}^{2}$ is considered class I obese. BMI from 35 to $39.9 \mathrm{~kg} / \mathrm{m}^{2}$ is class II obese, and above $40 \mathrm{~kg} / \mathrm{m}^{2}$ is class III category for obesity. BMI greater than $30 \mathrm{~kg} / \mathrm{m}^{2}$ have a $55 \%$ increased risk of mortality, $70 \%$ risk of coronary artery disease, $75 \%$ risk of stroke, and $400 \%$ increased risk of diabetes mellitus. In 2016, more than 1.9 billion adults aged 18 years and older were overweight. Of these, over 650 million adults were obese. In 2016, 39\% of adults aged 18 years and over (39\% of men and $40 \%$ of women) were overweight. Overall, about $13 \%$ of the world's adult population ( $11 \%$ of men and $15 \%$ of women) were obese in $2016 .^{5}$

In 2020, ${ }^{6}$ the WHO and World Obesity Federation recognized the global BMI rankings with Narau on the top position with $61 \%$ of population with an average BMI above $30 \mathrm{~kg} / \mathrm{m}^{2}$. Kuwait is ranked number 4 obese country in the world with $37.9 \%$ population with an average $\mathrm{BMI}$ of $30 \mathrm{~kg} / \mathrm{m}^{2}$.

\section{Current Management of Obesity}

The available options for weight loss management include intensive lifestyle modification, proven to show modest change in weight. Pharmacotherapy has shown to help weight loss by 3-9\% compared to lifestyle modification alone but with unfavorable side effects. Weight loss achieved by lifestyle modification and pharmacological therapies are very difficult to maintain due to high changes of relapse and weight gain. Bariatric surgery (BS) remains the effective and durable option for obesity management.

Weight loss from BS is based on two general principlesdecrease the gastric volume (restrictive physiology) and decrease the absorption of food (malabsorption).

The available procedures for BS include Roux-en-Y gastric bypass, laparoscopic sleeve gastrectomy, adjustable gastric band, vertical band gastroplasty, duodenal switch, and biliopancreatic diversion.
Department of Medicine, Division of Gastroenterology and Hepatology, University of Rochester Medical Center, Rochester, New York, USA

Corresponding Author: Truptesh H Kothari, Department of Medicine, Division of Gastroenterology and Hepatology, University of Rochester Medical Center, Rochester, New York, USA, Phone: +1 585-275-4711, e-mail:Truptesh_kothari@urmc.rochester.edu

How to cite this article: Kothari TH. Endoscopic Management of Obesity 2020. J Postgrad Med Edu Res 2021;55(1):2-7.

Source of support: Nil

Conflict of interest: None

\section{Evolution of Bariatric Endotherapy}

The complication risk for BS is approximately $17 \%$ and the mortality rate has improved over the years. Of patients eligible for BS, only $\sim 1 \%$ undergo surgical intervention. ${ }^{7}$ The reason for less than $1 \%$ patients undergoing BS is multifactorial depending on the surgical cost, patient preference, access to care, and morbidity and mortality associated with surgery. This leads to a treatment gap for the remaining $99 \%$ obese population. As a result, bariatric endotherapy has evolved as an alternative for a vulnerable patient population that is not appropriate candidates for surgery and can also help reduce the complication rate of various surgeries in such population as a bridge therapy.

\section{TyPES OF BARIATRIC ENDOTHERAPY}

The bariatric endotherapy can be functionally classified into gastric, small bowel therapy, and outlet reduction therapy. The gastric therapy is based on the concept of limiting gastric volume and can be further categorized into three types-space-occupying devices, aspiration therapy, and endoscopic sleeve gastroplasty. ${ }^{8,9}$ The small bowel therapies are based on the principles of malabsorption. ${ }^{8,9}$ Outlet reduction therapy is mainly used for weight recidivism in patients with Roux-en-Y gastric bypass who has regained significant weight. Again the principle is to limit the gastric volume by reduction of the stoma size leading to early satiety. ${ }^{9}$ 


\section{Gastric Therapy}

\section{Space-occupying Devices}

Intragastric balloon (IGB) placement has become an increasingly attractive minimally invasive endoscopic option for weight loss, as it allows for earlier interventions for obese patients who are not surgical candidates, and serves as a bridge to surgery in the morbidly obese. ${ }^{9}$ The U.S. Food and Drug Administration (FDA) approved the Garren-Edwards Gastric Bubble (GEGB) in 1984 as an IGB for obesity. The balloon was withdrawn from the market in 1992 due to serious adverse effects. Various balloons were designed and used in other parts of the world but none of the IGB was approved till 2015. In July 2015, Orbera (Apollo Endosurgery) and Reshape Duo Integrated Dual Balloon system (Reshape Medical) were approved. The third balloon to be approved in September 2016 was Obalon (Obalon Therapeutics)..$^{9}$ The Orbera balloon is a medical-grade silicone sphere balloon, which is filled with $400-700 \mathrm{~mL}$ of saline. The balloon is implanted in the stomach maximal for 6 months. The Reshape Duo Integrated Dual Balloon system consists of two medical-grade silicone spheres joined by a flexible shaft. Each balloon is filled with $375-450 \mathrm{~mL}$ of saline dyed with methylene blue. The balloon is implanted in the stomach maximal for 6 months. The Obalon balloon consist of thin polymer ellipse filled with $250 \mathrm{~mL}$ of nitrogen mix gas; three balloons are swallowed by mouth over a period of 9-12 weeks. The balloons are removed endoscopically after 6 months from the time of first balloon administration. The other non-FDA-approved balloons include Spatz balloon (Spatz FGIA) and Elipse balloon (Allurion Technologies). The Spatz balloon consist of a spherical silicone balloon around a curved catheter that extends outside the balloon and is proposed to be implanted for 12 months. The Elipse balloon is the only balloon, which is swallowed and self-disintegrates after 4 months, not involving the use of endoscopy. The swallowed balloon is attached with a thin catheter, which will be helpful in filling of the saline into the balloon once swallowed. This balloon is a spherical balloon, filled with $550 \mathrm{~mL}$ of saline. The balloon is designed to be implanted in the stomach for 4 months. Other space-occupying devices include transpyloric shuttle (TPS) (BAROnova, Goleta, CA, USA)—approved in 2019 and Full Sense device (Baker, Foote, Kemmeter, Walburn [BFKW] LLC, Grand Rapids, MI, USA), not FDA approved (Table 1 and Fig. 1).
Transpyloric shuttle is placed through endoscopy. The TPS system consists of a large and small bulb connected by a flexible silicone tether and an endoscopic delivery device. During delivery, the large bulb is distended with an internal coil, so the larger bulb gets locked in the stomach and with the help of peristalsis, the small bulb remains in the duodenum, which in turn will delay gastric emptying by intermittent sealing of pylorus with peristalsis.

Clinical evaluation of the Orbera device was performed in a prospective randomized controlled, comparative clinical study using 125 subjects in the treatment group and 130 subjects in the control group with BMI of $30-40 \mathrm{~kg} / \mathrm{m}^{2}$. The treatment group underwent Orbera placement followed by removal after 6 months. Both groups participated in a 12-month behavioral modification program. The effectiveness of the study was measured with two co-primary endpoints. This included, first, the mean percent excess weight loss (EWL) at 9 months ( 3 months after the balloon was removed) and, second, if $>30 \%$ of Orbera-treated subjects achieved significantly greater (>15\% estimated weight loss) weight loss over the mean \%EWL of the control group. The study did not meet its first co-primary endpoints as the mean \%EWL did not meet the $95 \%$ lower bound confidence interval, although the study did satisfy the second co-primary endpoint with $45.6 \%$ Orbera-treated patients exceeding $15 \%$ mean EWL over the control subjects. Total body weight loss in the Orbera group was noticed to be a mean of 10.2 and $9.1 \%$ at 6 and 9 months after balloon insertion, respectively. Significant weight loss was observed within the Orbera group as compared to the control group with a mean\% excess weight loss with ideal weight defined as BMI of 25 . It was found to be $38.4 \%$ at month $6,34.6 \%$ at month $9,29 \%$ at month 12 as compared to 12.1 , 12.3 , and $11.1 \%$ in the control group with a $p$ value of $<0.001$. The $\%$ total body weight loss of $10.2,9.1$, and $7.6 \%$ in the Orbera and $3.3,3.4$, and $3.1 \%$ in the control group at 6,9 , and 12 months after the insertion of the balloon with a $p$ value of $<0.001$. Secondary effectiveness of the intervention was measured by the impact of treatment on comorbid conditions such as hypertension, type 2 diabetes, and dyslipidemia at months 6,9, and 12. It was noticed that both groups experienced a comparable decrease in the severity of the comorbid conditions, which may be as a result of a common factor in both groups such as diet and exercise. $p$ values were not

Table 1: Various Food and Drug Administration (FDA)-approved and nonapproved gastric endoscopic bariatric therapy options

\begin{tabular}{|c|c|c|}
\hline \multicolumn{3}{|l|}{ Intragastric balloons } \\
\hline Orbera & FDA Approved, 2015 & Elastic spherical balloon that induces early satiety by occupying space. \\
\hline Reshape Duo & FDA Approved, 2015 & Space-occupying device. \\
\hline Spatz adjustable balloon system & Not FDA-approved & \\
\hline Obalon gastric balloon & FDA approved, 2016 & $\begin{array}{l}\text { Gas-filled balloon with maximal volume of } 250 \mathrm{~mL} \text {. Space-occupying, } \\
\text { induces satiety. }\end{array}$ \\
\hline \multicolumn{3}{|c|}{ Other space-occupying endoscopic bariatric therapy } \\
\hline Transpyloric shuttle & FDA-approved, 2019 & $\begin{array}{l}\text { Endoluminally delivered silicone funnel that delays gastric emptying by } \\
\text { intermittent sealing of pylorus with peristalsis. }\end{array}$ \\
\hline Full sense device & Not FDA-approved & $\begin{array}{l}\text { Fully covered gastroesophageal stent that induces satiety by ensuring that } \\
\text { the gastric disk applies pressure on the gastric cardia. }\end{array}$ \\
\hline \multicolumn{3}{|l|}{ Aspiration therapy } \\
\hline A-tube and aspire assist device & FDA-approved, 2016 & $\begin{array}{l}\text { Percutaneous endoscopic gastrostomy tube that allows for aspiration of } \\
30 \% \text { of the ingested meal. }\end{array}$ \\
\hline \multicolumn{3}{|l|}{ Gastroplasty techniques } \\
\hline $\begin{array}{l}\text { Endoscopic sleeve gastroplasty with } \\
\text { overstitch endoscopic suturing device }\end{array}$ & FDA-approved & $\begin{array}{l}\text { Reduction of the stomach area along the greater curvature by endolumi- } \\
\text { nally placing closely spaced sutures. Endoscopically creates a sleeve. }\end{array}$ \\
\hline $\begin{array}{l}\text { Primary obesity surgery endoluminal } \\
\text { (POSE) }\end{array}$ & Not FDA-approved & $\begin{array}{l}\text { Reduction of accommodation by placing a transmural tissue anchor plica- } \\
\text { tion in the gastric fundus and distal gastric body. }\end{array}$ \\
\hline
\end{tabular}



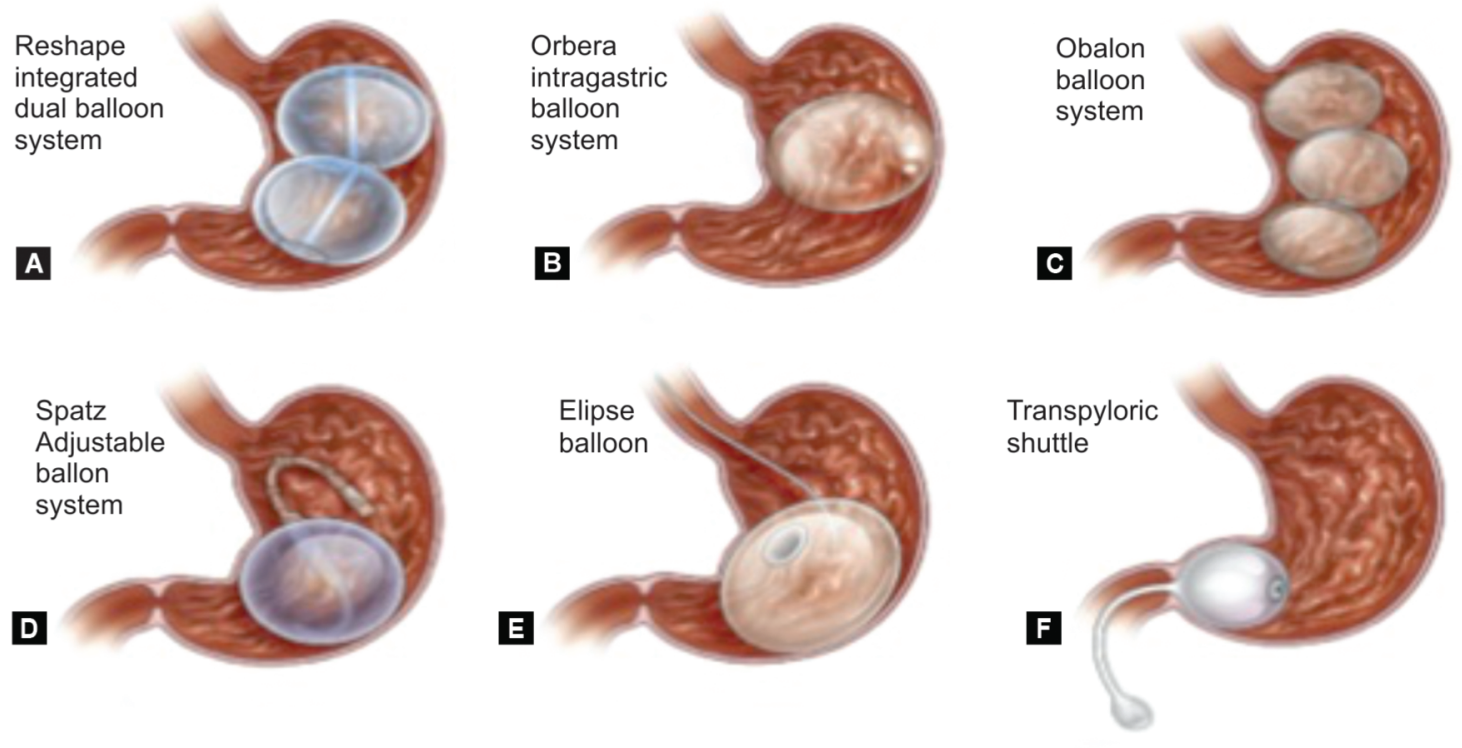

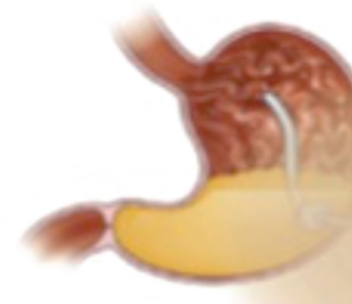

G Aspiration therapy

Figs $1 \mathrm{~A}$ to I: Gastric therapy

statistically significant to prove a difference between the Orbera and control groups when comparing the decrease in severity of hypertension, diabetes, and dyslipidemia. The Orbera pivotal trial revealed that patients could expect to achieve three times the weight loss at 6 months as compared to diet and exercise alone, majority of which is lost in the first 3 months.

A longitudinal and interventional study was performed in obese patients over 6 months after placement of an IGB aimed to study the effect of the treatment on lung function, BMI, and DXA parameters. It was noted that lung volumes were significantly reduced at 6 months after balloon placement. A drop in BMI was also noticed from $39.1 \mathrm{~kg} / \mathrm{m}^{2}$ to $34.5 \mathrm{~kg} / \mathrm{m}^{2}$. Considerable improvement in body fat distribution was also reported using DXA measurements of body fat. ${ }^{8}$

A randomized clinical study was performed to evaluate the safety and efficacy of the Reshape dual balloon system (DBS) by comparing two groups of patients: one with DBS treatment along with diet and exercise and one that was a control group with diet and exercise only (Fig. 2). The study included a total of 326 individuals with 187 in the DBS group and 139 in the control group.
The BMI of the targeted patient population was between $30 \mathrm{~kg} / \mathrm{m}^{2}$ and $40 \mathrm{~kg} / \mathrm{m}^{2}$. The study revealed a significant effect in the DBS group as compared to control. The effectiveness was measured using two co-primary endpoints. The first primary endpoint was defined by the percent excess weight loss (\%EWL) and the second primary endpoint measured if more than 35\% achieved a $25 \%$ EWL in the treatment group at 24 weeks when the dual balloon system was retrieved. This pivotal trial successfully met both the co-primary endpoints. It was found that the weight loss was more than double as compared to the control group along with a \%EWL of $25.1 \%$ in the DBS group (intention-to-treat). This is significantly greater than the control group with a \%EWL of $11.3 \%$. The second primary endpoint was also met as there was a $49.1 \%$ difference in the treatment group who achieved a $25 \% \mathrm{EWL}$; this was considerably over the $35 \%$ response rate. ${ }^{10-12}$

\section{Aspiration Therapy}

Aspiration therapy was approved for use in patients with a BMI between $35 \mathrm{~kg} / \mathrm{m}^{2}$ and $55 \mathrm{~kg} / \mathrm{m}^{2}$. A gastrostomy tube is placed endoscopically with a standard pull technique. After 1-2 weeks, 

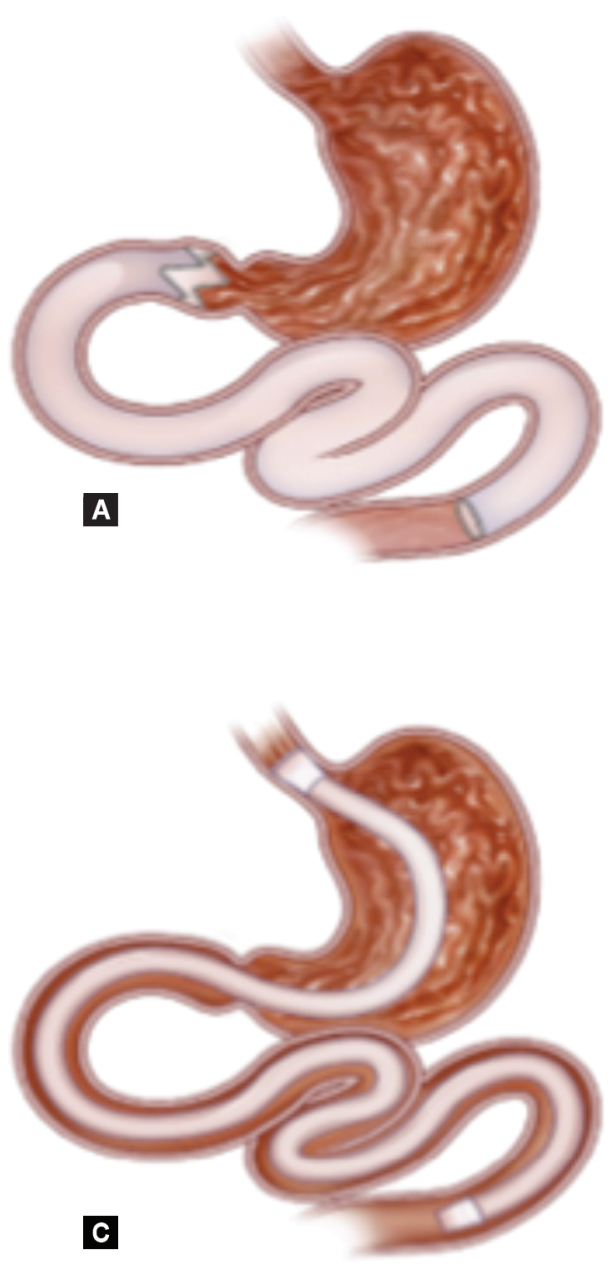

Figs $2 \mathrm{~A}$ to $\mathrm{D}$ : Small bowel therapy

the tube is cut down to the skin surface and the skin port is used for aspiration sessions. The session are performed mostly 20 minutes after meal and carried out for twice a day with the goal to remove $25-30 \%$ of calories consumed per meal. The mechanism contributed to the principle of weight loss with aspiration of calories and behavioral modification, which led to decrease overall intake of food. ${ }^{13}$

The open-label randomized controlled trial examined 171 patients (Active $n=111, \mathrm{BMI} 42.0 \pm 5.1 \mathrm{~kg} / \mathrm{m}^{2}$, control $n=60, \mathrm{BMI}-$ $40.9 \pm 3.9 \mathrm{~kg} / \mathrm{m}^{2}$ ) across 10 centers in the United States. The \% TBWL in subjects who completed the 12-month trial (active $n=82$, control $n=31$ ) was $14.2 \pm 9.8 \%$ and $4.9 \%$ in the active and control group, respectively $(p<0.01)$ with $58.6 \%$ of all active subjects reaching $>10 \%$ TBWL compared with $22.1 \%$ of all control groups. ${ }^{14}$ The most frequently reported adverse events were abdominal pain in the perioperative period (37.8\%) and peristomal granulation tissue in the postoperative period (40.5\%).

\section{Endoscopic Sleeve Gastroplasty}

Endoscopic sleeve gastroplasty (ESG) is an incisionless, minimally invasive technique, approved for primary treatment of obesity in

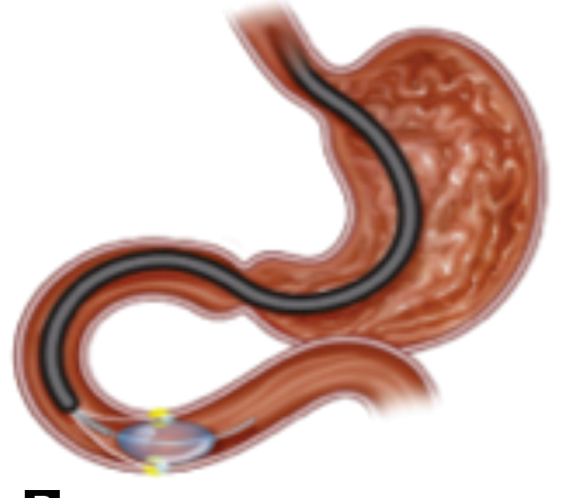

B

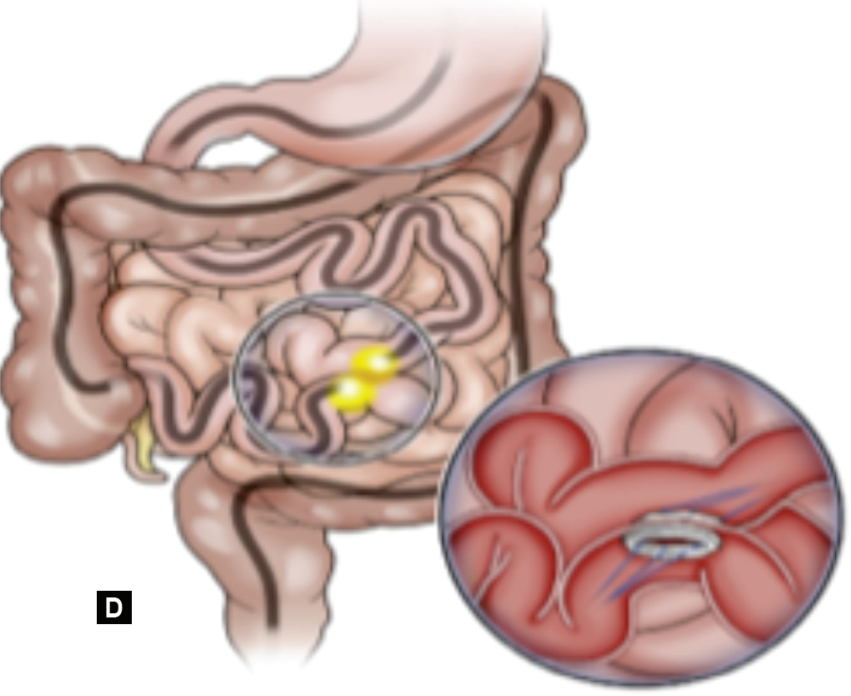

2016. The ESG reduces the gastric capacity by creating a restrictive sleeve through a series of endoluminal full-thickness triangular sutures extending from the prepyloric antrum to the GEJ. This technique is accomplished using an endoscopic suturing device (Overstitch, Apollo Endosurgery, Austin, TX).

With the aim to report the long-term response rate and validity of the technique, a multicenter retrospective analysis of prospectively maintained databases of ESG patients between January 2013 and December 2015 was performed. ${ }^{15}$ A total of 248 patients (mean age $44.5 \pm 10$ years, $73 \%$ female) were included in the analysis. Baseline BMI was $37.8 \pm 5.6 \mathrm{~kg} / \mathrm{m}^{2}$. At 6 and 24 months, 33 and 35 patients were lost to follow-up, respectively. At 6 and 24 months, \%TBWL was 15.2 (95\% Cl 14.2-16.3) and 18.6 (15.7-21.5), respectively. Weight loss was similar between centers at both follow-up intervals. At 24 months, $\%$ of patients achieving $\geq 10 \%$ TBWL was 84.2 and $53 \%$ with PP (per protocol) and ITT (intention to treat) analyzes, respectively. The weight loss $>10 \%$ TBWL at 24 months was determined by the weight loss $>10 \%$ TBWL at 6 months. If the weight loss at 6 months was $<10 \%$ TBWL, adjunct therapy should be offered to patients to augment the weight loss. 
- Small bowel interventions are not FDA approved and though novel therapies are in human trials (Table 2 and Fig. 3)

- Transoral outlet reduction endoscopy (Fig. 2)

Weight recidivism is a continuing issue in patients who have undergone Roux-en-Y gastric bypass. A prospective study of 150 patients was performed in patients who regained weight regain post-Roux-en-Y gastric bypass (RYGB) surgery. Patients with gastrojejunal anastomosis (stoma) aperture larger than $15 \mathrm{~mm}$ were included in the study. This study aimed to recognize the long-term benefits of management of dilated anastomosis aperture post-RYGB using an endoscopic procedure called transoral outlet reduction endoscopy (TORe). After performing argon plasma coagulation around the stoma to devitalize the tissue, the endoscopic suturing device (Overstitch, Apollo Endosurgery, Austin, TX) is used to perform either interrupted or uninterrupted sutures to reduce the stoma size to $8 \mathrm{~mm}$. Following the procedure, the patients were kept on a strict diet regimen of 6 weeks. The study focused on trending weight loss at 3, 6, 12, 24, and 36 months after completion of the TORe procedure. It was reported that a weight loss of 9-11 kg and a BMI loss of $3 \mathrm{~kg} / \mathrm{m}^{2}$ was achieved as a result. This was as a result of a decrease in aperture size from $24.1+1 \mathrm{~mm}$ to $9.0+0.2 \mathrm{~mm}$ The adverse effects were limited to abdominal pain in $4 \%$ patients, gastrointestinal bleeding in 3.3\%, and nausea in $2.0 \%$. It was shown that a greater reduction in anastomotic aperture was associated with a greater postprocedural weight reduction. ${ }^{16}$

Table 2: Small bowel endoscopic bariatric therapy options

\section{Gastrointestinal bypass sleeves \\ Endobarrier}

Gastroduodenojejunal bypass sleeve

Other small bowel interventions

Duodenal mucosal resurfacing

Self-assembling magnets for endoscopy
Not FDA-approved

Not FDA-approved

Not FDA-approved

Not FDA-approved
Mechanical barrier for the food to bypass the duodenum and proximal jejunum. Prevents mixing of food with pancreatobiliary secretions.

Sleeve that can be secured at the gastroesophageal junction, allows food to bypass the stomach, duodenum, and proximal jejunum. Acts similarly to gastric bypass surgery.

Radiofrequency ablation of the superficial duodenal mucosa.

Self-assembling magnets that create compression of the anastomotic sites such as gastrojejunostomies, gastroileostomies, and duodenoileostomies.
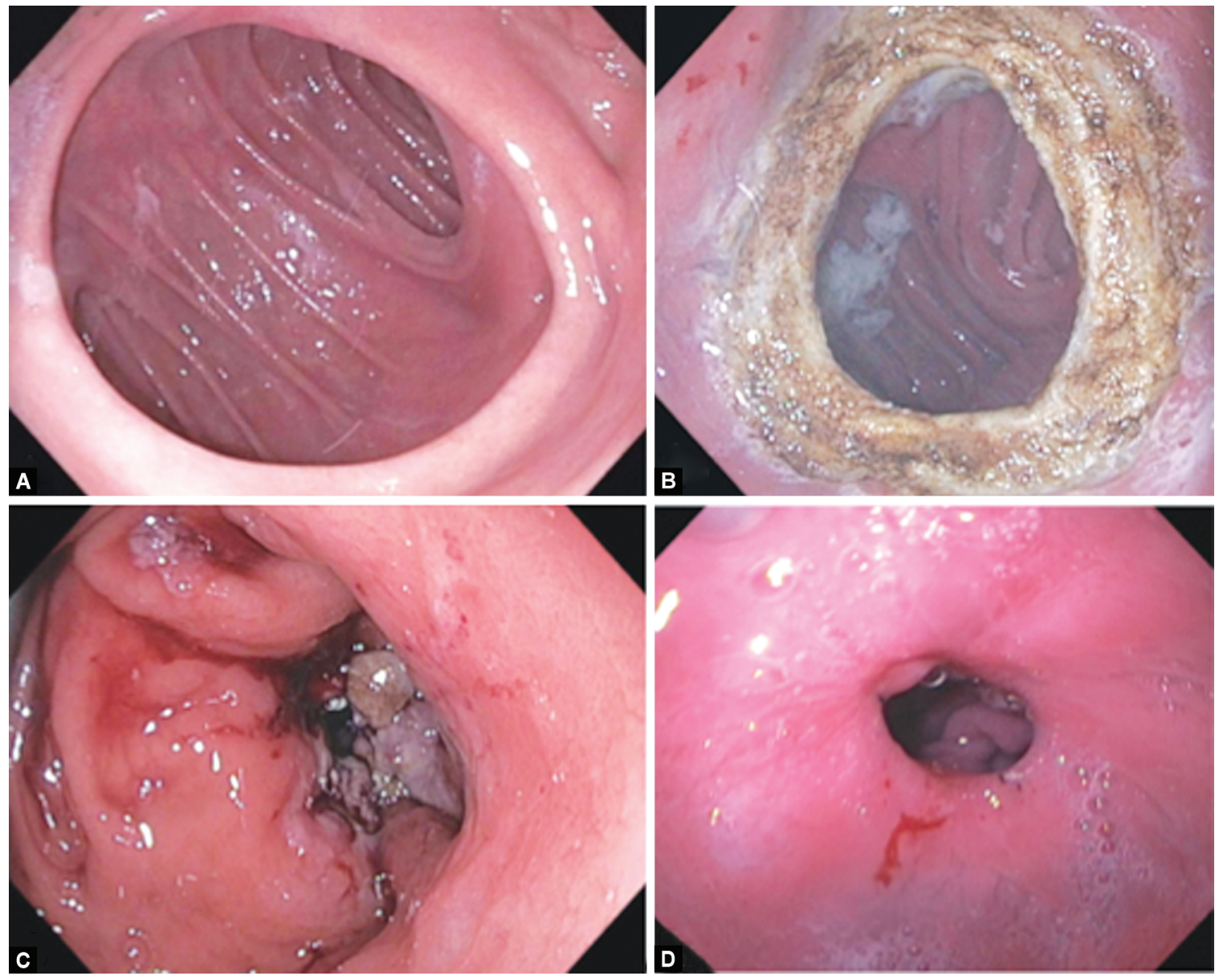

Figs 3A to D: Transoral outlet reductions 
Obesity is one of the leading health problems in the United States today and is very challenging to manage. Despite numerous management options varying from lifestyle modifications to BS, obesity remains a problem unsolved. Obesity comes with a wide array of comorbidities increasing the financial burden of this widespread epidemic even further. As a result, it has become one of the top priorities in today's health care..$^{17}$

The ASGE Endovators task force published its first position statement on application of endobariatric therapies for obesity in 2017, which emphasized on training of physician. ${ }^{18}$ "Training should focus both on technical skills (likely device-specific) as well as general knowledge of obesity medicine, nutrition, diet, and lifestyle management. A uniform training curriculum and credentialing process would be optimal to ensure minimum standards among physicians."

Endoscopic techniques allow for the management of obesity in a less invasive manner and help prevent the associated risks of the bariatric surgical procedures. It also allows for a holistic approach to manage obesity with endoscopic intervention being the primary tool complemented by its behavioral modification program and comprehensive follow-up strategies. Although some of the therapies currently remain under FDA evaluation and trials, the emergence of endoscopic bariatric therapies holds a promising future in the way obesity will be managed. This is indeed a revolutionary step toward medical and surgical management.

\section{References}

1. Obesity: preventing and managing the global epidemic Report of a WHO consultation. World Health Organ Tech Rep Ser 2000;894(ixii):1-253.

2. Peeters A, Barendregt $\mathrm{JJ}$, Willekens $\mathrm{F}$, et al. Obesity in adulthood and its consequences for life expectancy: a life-table analysis. Ann Intern Med 2003;138(1):24-32. DOI: 10.7326/0003-4819-138-1-20030107000008.

3. Whitlock G, Lewington S, Sherliker P, et al. Body mass index and cause specific mortality in 900000 adults: collaborative analyses of 57 prospective studies. Lancet 2009;373(9669):1083-1096. DOI: 10.1016/S0140-6736(09)60318-4.

4. Ogden $\mathrm{CL}$, Carroll MD, Fryar CD, et al. Prevalence of obesity among adults and youth: United States, 2011-2014. NCHS Data Brief 2015;219:1-8.

5. World Health Organization. Fact Sheet. Obesity and Overweight http://www.who.int/mediacentre/factsheets/fs311/en.
6. World Health Organization. Fact Sheet. Obesity and Overweight http://worldpopulationreview.com/countries/most-obese-countries.

7. Ma IT, Madura 2nd JA. Gastrointestinal complications after bariatric surgery. Gastroenterol Hepatol (N Y) 2015;11(8):526-535.

8. Abu Dayyeh BK, Kumar N, Edmundowicz SA, et al. ASGE bariatric endoscopy task force systematic review and meta-analysis assessing the ASGE PIVI thresholds for adopting endoscopic bariatric therapies. Gastrointest Endosc 2015;82(3):425-438.e5. DOI: 10.1016/j. gie.2015.03.1964.

9. Kumar N. Weight loss endoscopy: development, applications, and current status. World J Gastroenterol 2016;22(31):7069-7079. DOI: 10.3748/wjg.v22.i31.7069.

10. Yanovski SZ, Yanovski JA. Long-term drug treatment for obesity. JAMA 2014;311(1):74. DOI: 10.1001/jama.2013.281361B E. The effectiveness and risks of bariatric surgery an updated systematic review and meta-analysis, 2003-2012.

11. Mafort TT, Madeira E, Madeira M, et al. Six-month intragastric balloon treatment for obesity improves lung function, body composition, and metabolic syndrome. Obes Surg 2013;24(2):232-240. DOI: 10.1007/ s11695-013-1061-5.

12. Ponce J, Woodman G, Swain J, et al. The REDUCE pivotal trial: a prospective, randomized controlled pivotal trial of a dual intragastric balloon for the treatment of obesity. Surg Obes Rel Disea 2015;11(4):874-881. DOI: 10.1016/j.soard.2014.12.006.

13. Sullivan $S$, Stein $R$, Jonnalagadda $S$, et al. Aspiration therapy leads to weight loss in obese subjects: a pilot study. Gastroenterology 2013;145(6):1245-1252. DOI: 10.1053/j.gastro.2013.08.056.

14. Thompson CC, Abu Dayyeh BK, Kushner R, et al. Percutaneous gastrostomy device for the treatment of class II and class III obesity: results of a randomized controlled trial. Am J Gastroenterol 2017;112(3):447-457. DOI: 10.1038/ajg.2016.500.

15. Lopez-Nava G, Sharaiha RZ, Vargas EJ, et al. Endoscopic sleeve gastroplasty for obesity: a multicenter study of 248 patients with 24 months follow-up. Obes Surg 2017;27(10):2649-2655. DOI: 10.1007/ s11695-017-2693-7.

16. Kumar N, Thompson CC. Mo2038 transoral outlet reduction (TORe) for weight regain after gastric bypass: Long-term follow-up and number needed to treat. Gastroenterology 2014;146(5). DOI: 10.1016/ s0016-5085(14)62627.

17. Truptesh K, Paridhi M, Shivangi K, et al. Endoscopic bariatric interventions in the management of obesity: the era of non-surgical management. Frontiers in Endoscopy, Series \# 33 2017;XLI(1):14-23.

18. Ryou M, McQuaid KR, Thompson CC, et al. ASGE endovators summit: defining the role and value of endoscopic therapies in obesity management. Gastrointest Endosc 2017;86(5):757-767. DOI: 10.1016/j. gie.2017.08.004. 